\title{
Algas planctônicas flageladas e cocoides verdes de um lago no Parque Beija-Flor, Goiânia, GO, Brasil
}

\author{
Emmanuel Bezerra D’Alessandro ${ }^{1,2,3}$ e Ina de Souza Nogueira ${ }^{2}$
}

Recebido: 28.09.2016; aceito: 02.05.2017

\begin{abstract}
Planktonic flagellate and coccoid green algae in a lake of Parque Beija-Flor, Goiânia, Goiás State, Brazil). The public parks of Goiânia are socioenvironmentally important to the city, however, little is known about their quality and aquatic biodiversity. This study is focused on the Chlorophyceae and Trebouxiophyceae (Chlorophyta) of a lake in an urban park located in the municipality of Goiânia, Goiás State, during a short period of rainfall and drought. Weekly samplings were carried out during August 2007 and January 2008 at three sampling sites, according to the usual techniques for floristic analysis. We identified 25 infrageneric taxa: 16 Sphaeropleales, six Chlorellales, one Chlamydomonales, one Chlorococcales, and one taxon of Trebouxiophyceae of uncertain position. Pandorina morum, Lacunastrum gracillimum, Desmodesmus intermedius var. acutispinus and Pachycladella komarekii represent new records for the State of Goiás.
\end{abstract}

Keywords: Chlorophyceae, Goiânia, Sphaeropleales, Trebouxiophyceae, urban lake

RESUMO - (Algas planctônicas flageladas e cocoides verdes de um lago no Parque Beija-Flor, Goiânia, GO, Brasil). Os parques públicos de Goiânia apresentam importância socioambiental para a cidade, no entanto pouco se conhece sobre a sua qualidade e biodiversidade aquática. O presente estudo é focado nas Chlorophyceae e Trebouxiophyceae (Chlorophyta) em um lago de parque urbano localizado no município de Goiânia, GO, durante um curto período de chuva e de seca. As coletas foram realizadas semanalmente durante agosto de 2007 e janeiro de 2008, em três estações de amostragem, de acordo com as técnicas usuais para análises florísticas. Foram identificados 25 táxons infragenéricos: 16 Sphaeropleales, seis Chlorellales, um Chlamydomonales, um Chlorococcales e um táxon de Trebouxiophyceae de posição incerta. Pandorina morum, Lacunastrum gracillimum, Desmodesmus intermedius var. acutispinus e Pachycladella komarekii são registradas pela primeira vez para o Estado de Goiás.

Palavras-chave: Chlorophyceae, Goiânia, Sphaeropleales, Trebouxiophyceae, lago urbano

\section{Introdução}

Chlorophyta é composta por diferentes tipos de organizações morfológicas, nas quais destacam-se organismos flagelados (Chlorophyceae) ou cocoides (Chlorophyceae e Trebouxiophyceae) presentes em diferentes ambientes lênticos urbanos (Komarek \& Fott 1983), e segundo Paul et al. (2012) Chlorophyta tem correlação positiva com ambientes hídricos urbanos devido a influência do uso do solo.

No início do século 21, a sistemática de algas verdes cocoides passou por constantes modificações fundamentadas no estudo do DNA de várias espécies. Pröschold \& Leliaert (2007) apresentam uma retrospectiva dos arranjos taxonômicos das algas verdes com base na morfologia e na ultraestrutura, e ainda expõem informações da biologia molecular que até aquele momento haviam sido aceitas amplamente pelos taxonomistas. Estes autores fazem uma analogia entre o clássico e o moderno concluindo que como a maioria dos gêneros em Chlorophyta são polifiléticos seria necessário uma revisão robusta a luz do código internacional de botânica.

Como o grupo de algas verdes é muito amplo, existe no momento atual para Chlorophyta continentais um dos primeiros arranjos taxonômicos efetuados por Krienitz \& Bock (2012) com a síntese de dados morfológicos e moleculares, o que conduz uma abordagem da taxonomia polifásica. Os autores

1. Parte do Trabalho de Conclusão de Curso do primeiro Autor

2. Universidade Federal de Goiás, Instituto de Ciências Biológicas I, Departamento de Botânica, Laboratório de Gerenciamento Ambiental de Recursos Hídricos (LAMARH), Av. Esperança, s.n., Campus Samambaia, 74690-900 Goiânia, Goiás, Brasil

3. Autor para correspondência: dalessandro.e.b@gmail.com 
propuseram uma nova organização fundamentada nas principais linhagens de algas verdes e também apresentaram uma lista de táxons harmonizados para a Europa, na qual fazem uma análise filogenética molecular incluindo as antigas designações dos táxons confirmadas ou revistas informando os nomes genéricos atuais. Muito destes táxons também são de ocorrência cosmopolita e foram registrados nos ambientes tropicais. Posterior a este artigo destacam-se mais de forma específica e com a mesma tendência de abordagem os artigos de Bock et al. (2013), Hegewald et al. (2013), Krienitz et al. (2015) entre outros.

Observa-se que Chlorophyta flageladas e cocoides com formação de zoósporos estão inseridas em Chlorophyceae (Chlamydomonadales), enquanto que as demais cocoides com formação de autósporos no ciclo reprodutivos estão posicionadas tanto em Chlorophyceae como em Trebouxiophyceae (Pröschold \& Leliaert 2007, Grahan et al. 2009, Krienitz \& Bock 2012, Ruggiero et al. 2015).

Em Chlorophyceae inclui-se espécies que possuem aparato flagelar do tipo diretamente oposto (DO) ou em sentido horário (CW) e estão distribuídas mundialmente podendo ser registradas em quase todos os habitats (Pröschold \& Leliaert 2007, Krienitz \& Bock 2012).

Algas verdes flageladas estão inseridas em Prasynophyceae e Chlorophyceae, sendo esta última de maior distribuição em ambientes aquáticos continentais cuja ordem Chlamydomonadales apresenta organismos unicelulares ou coloniais com 2-4 flagelos apicais do tipo CW, células com ou sem papilas ou vacúolos pulsáteis, mas geralmente com estigmas (Ettl 1983, Grahan et al. 2009, Ruggiero et al. 2015). Dentro desta ordem destacam-se as Volvocaceae que são caracterizadas por organismos cenobiais flagelados com ampla distribuição geográfica.

Chlorophyta cocoide tem como destaque em Chorophyceae as Sphaeropleales e para Trebouxiophyceae as Chlorellales cuja organização cocoides permite uma estratégia adaptativa ao plâncton e a manutenção em ecossistemas lênticos, preferencialmente enriquecidos (Komárek \& Fott 1983, Reynolds 2006).

Sphaeropleales apresenta organismos unicelulares, filamentosos ou cenobiais com o aparato flagelar com corpos basais diretamente opostos (DO) (Buchheim et al. 2001). Chlorellales compreende indivíduos com organização morfológica em unicelulares, colôniais e aparato flagelar CCW (Krienitz \& Bock 2012, Pröschold \& Leliaert 2007).
Chlorophyta cocoides e flageladas em ambientes de águas continentais, apresentam preferências ambientais presentes em pequenos lagos urbanos eutróficos (Padisák et al. 2009). A biodiversidade em ambientes aquáticos urbanos é fortemente influenciada pela ação antropogênica associada à remoção de vegetação marginal (Hassall 2014). No país, Nogueira \& Leandro-Rodrigues (1999) apresentaram um panorama sobre registro de algas em lagos urbanos em diferentes regiões geográficas e Menezes et al. (2015) proporcionam um cenário de algas epicontinentais de todo o Brasil. Desse período até o presente destacam-se os artigos de Giani et al. (1999), Keppeler et al. (1999), Silva (1999), Ferreira \& Menezes (2000), Ramírez \& Bicudo (2002), Alves-da-Silva \& Bridi (2004a, 2004b), Alves-daSilva \& Hahn (2001, 2004), Matsuzaki et al. (2004), Ferraguiti et al. (2005), Lopes et al. (2005), Tucci et al. (2006), Alves-da-Silva \& Schüler-da-Silva (2007), Dellamano-Oliveira et al. (2008), Gentil et al. (2008), Nogueira et al. (2008), Nogueira \& Oliveira (2009), Nabout \& Nogueira (2011), Rosini et al. (2012) e Rosini et al. (2013).

No Brasil existem alguns estudos em ambientes aquáticos urbanos, porém observa-se um predomínio de algas flageladas e ou cocoides verdes planctônicos registrados em diferentes artigos de cunho florísticos ao longo do país, dos quais se destacam: Godinho et al. (2010), Hentschke \& Torgan (2010), Menezes et al. (2011), Bicudo (2012), Domingues \& Torgan (2012), Hentschke \& Prado (2012), Rosini et al. (2012), Alves et al. (2014), Aquino et al. (2014), Ramos et al. (2014; 2015a; 2015b), Riediger et al. (2014) e Tucci et al. (2014).

Existem 12 trabalhos que apresentam para o Estado de Goiás informações de Chlorophyta flageladas e ou cocoides para ambientes aquáticos artificiais: Campos \& Macedo-Saidah (1990), Crispim et al. (1992), Brandão \& Kravchenko (1997), Bazza (1998), Nogueira \& Leandro-Rodrigues (1999), Silva et al. (2001), Felisberto et al. (2001), Felisberto \& Rodrigues (2002), Nogueira et al. (2002), Nogueira et al. (2008), Nogueira \& Oliveira (2009) e Nabout \& Nogueira (2011). Sobre os lagos urbanos de Goiânia, destacam-se os trabalhos de Nogueira \& LeandroRodrigues (1999), Nogueira et al. (2008), Nogueira \& Oliveira (2009) e Nabout \& Nogueira (2011).

O município de Goiânia tem como um dos maiores atrativos os parques e bosques públicos que somam 191 unidades (Amma 2016) e observa-se que em cerca de 50\% tem lagos urbanos artificiais. Estes 
começaram a ser construídos na década de 50 para interagirem a população nos mais diferentes tipos de lazer (Nardini \& Nogueira 2008). No entanto, pouco se sabe da qualidade e da biodiversidade aquática. $\mathrm{O}$ presente estudo é parte do projeto de ficoflórula dos lagos urbanos de Goiânia, e buscou-se inventariar Chlorophyta flageladas e cocoides ocorrentes no Parque Beija-Flor (região norte) durante um curto período de seca e de chuva.

\section{Material e métodos}

O Parque Beija-Flor $\left(49^{\circ} 13^{\prime} \mathrm{W}\right.$ e $\left.16^{\circ} 39^{\prime} \mathrm{S}\right)$ localiza-se na região norte do município de Goiânia, GO, construído em 2007 e encontra-se dentro de uma área urbanizada e residencial. Foram utilizadas as nascentes para a construção de pequenos lagos artificiais e as demais áreas foram drenadas (Amma 2004). Três pontos amostrais foram selecionados, sendo dois em lagos artificiais e um em canal de drenagem. O lago principal (ponto 1) possui área superficial de 4.393,22 $\mathrm{m}^{2}$ e perímetro de 337,94 m, o lago secundário (ponto 3 ) possui área superficial de $102 \mathrm{~m}^{2}$ e perímetro de $45 \mathrm{~m}$ e o canal de abastecimento (ponto 2) possui $166 \mathrm{~m}$ de comprimento e $1 \mathrm{~m}$ de largura (Amma 2004) (figura 1).

Amostras subsuperficiais foram coletadas semanalmente através de processos seletivos (rede de plâncton $25 \mu \mathrm{m}$ ) abrangendo um curto período de seca (agosto a setembro/2007) e chuva (janeiro a fevereiro/2008). Parte das amostras foi fixada com solução de Transeau (Bicudo \& Menezes 2006) e outra parte mantida viva para estudo. As amostras foram

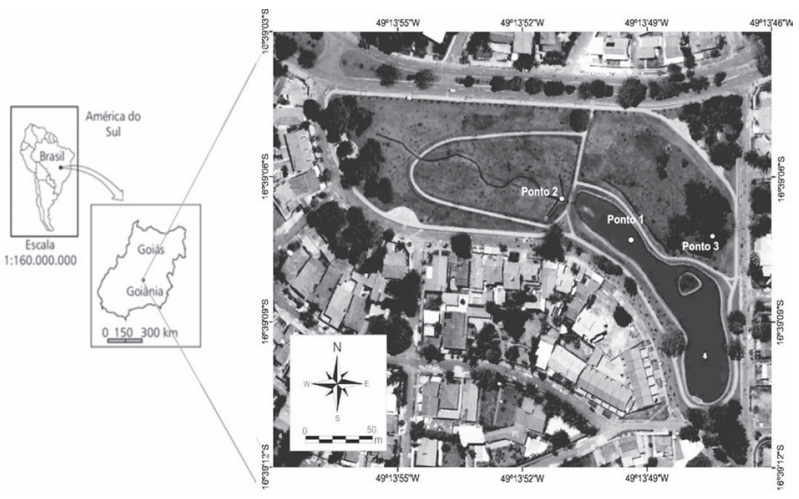

Figura 1. Parque Beija-Flor, município de Goiânia, GO, Brasil, com os pontos amostrais: lago principal (ponto 1), canal de abastecimento do lago principal (ponto 2) e lago secundário (ponto 3).

Figure 1. Beija-Flor Park, Goiânia city, Goiás State, Brazil, with sampling points: main lake (point 1), main lake supply channel (point 2) and secondary lake (point 3 ). examinadas em microscópio óptico Zeiss Axioscop 40, esquematizadas e microfotografadas.

O sistema de classificação adotado para as classes taxonômicas foi o de Krienitz \& Bock (2012) com ajustes de artigos posteriores. Para as Radiococcaceae adotou-se o sistema de Kostikov et al. (2002). A literatura utilizada na identificação de morfoespécies de algas cocoides foi: Komárek \& Fott (1983), Komárek (1983), Comas (1996), Hindák (1984, 1988, 1990); Ettl (1983), com as devidas atualizações por Bock et al. (2010), Hegewald et al. (2010), Krienitz et al. (2011a, 2011b, 2012) e Bock et al. (2013).

A distribuição geográfica dos táxons registrados foi fornecida apenas para o Estado de Goiás.

\section{Resultados e Discussão}

Foi identificado um total de 25 táxons, dos quais 13 gêneros foram de Chlorophyceae e sete de Trebouxiophyceae. Em Chlorophyceae foram registrados um táxon na ordem Chlamydomonadales, um na Chlorococcales e 16 na Sphaeropleales. Em Trebouxiophyceae foram identificados cinco táxons em Chlorellales e um Trebouxiophyceae incertae sedis.

Os 13 gêneros de Chlorophyceae registrados foram distribuídos em quatro táxons infragenéricos de Desmodesmus, três de Kirchneriella e os demais gêneros com um táxon em cada (Pandorina, Treubaria, Lacunastrum, Radiococcus, Raphidocelis, Selenastrum, Comasiella, Pectinodesmus, Scenedesmus, Tetrallantos e Westella).

Os seis gêneros de Trebouxiophyceae registrados no Parque Beija-Flor foram identificados em dois táxons infragenéricos de Hindakia e nos demais apenas uma espécie em cada gênero (Pachycladella, Micractinium, Mucidosphaerium, Dicloster e Lemmermannia).

Ao longo do estudo as espécies com maior frequência observada nas amostras foram Desmodesmus communis ( $52 \%$ do total de amostras) seguido de Lacunastrum gracillimum (47\%) e Mucidosphaerium pulchellum (42\%).

Classe Chlorophyceae

Ordem Chlamydomonadales

Família Volvocaceae

Gênero Pandorina Bory 1824

Pandorina morum (O.F. Mueller) Bory. Bory in Lamouroux, Bory de Saint-Vincent \& Deslongschamps, Pandorina, pp. 521-600. 1824.

Figuras 2 e 3 
Colônia elipsoide ou esférica, $44 \times 34 \mu \mathrm{m}$, mucilagem conspícua, 8-16 células distribuídas em camadas superpostas, extremamente compactas. Célula subpiramidal, monadoide, $11 \times 10 \mu \mathrm{m}$, polos arredondados voltados para o lado interno da colônia, cada uma com 2 flagelos, conspícuo, localizado anteriormente a célula, parede celular lisa, hialina, estigma conspícuo e localizado na porção apical, cloroplasto urceolado, único, parietal, 1 pirenoide.

Material examinado: BRASIL. GoIÁs: Goiânia, Parque Beija-Flor, Ponto 2, 26-VIII-2007, E.B. D'Alessandro (UFG40243); Ponto 3, 23-IX-2007, E.B. D'Alessandro (UFG40255).

Distribuição geográfica: Primeira citação da espécie para o Estado de Goiás.

Ordem Chlorococcales

Familia Treubariaceae

Gênero Treubaria Bernard 1908

Treubaria schmidlei (Schoder) Fott \& Kovácik. Preslia 47: 309. 1975.

\section{Figura 4}

Célula isolada, livre, tetraédrica, $10 \times 9 \mu \mathrm{m}$ de lado; 4 espinhos, hialinos, robustos, retos, $30 \times 6 \mu \mathrm{m}$; parede celular lisa, hialina, tênue; protoplasma esférico, distanciado da parede celular, cloroplasto único, parietal, 1 pirenoide. Reprodução por autósporos.

Material examinado: BRASIL. Goís: Goiânia, Parque Beija-Flor, Ponto 3, 2-IX-2007, E.B. D'Alessandro (UFG40247); Ponto 3, 23-IX-2007, E.B. D'Alessandro (UFG40255).

Distribuição geográfica: município de Goiânia: lago das Rosas (Nogueira et al. 2008).

Ordem Sphaeropleales

Família Hydrodityaceae

Gênero Lacunastrum H.McManus 2011

Lacunastrum gracillimum (West \& G. S. West) H. McManus. Journal of Phycology47(1): 128-129, fig. 4. 2011.

Figura 5

Cenóbio circular, plano, $65 \times 60 \mu \mathrm{m}, 16$ células dispostas concentricamente, espaços intercelulares presentes, igual ou maior que o diâmetro da célula. Células marginais poligonais ou aproximadamente em $\mathrm{H}$, parede celular lisa, as externas unidas entre si pela base, $15 \times 9 \mu \mathrm{m}, 2$ processos cilíndrico-truncados livres, estreitos, mais longo que a largura da célula, no mesmo plano, as internas fixas pelas extremidades, $10 \times 9 \mu \mathrm{m}$; cloroplasto único, parietal, ocupando todo processo. Reprodução por autósporo.

Material examinado: BRASIL. GoIÁs: Goiânia, Parque Beija-Flor, Ponto 2, 20-VIII-2007, E.B. D'Alessandro (UFG40240); Ponto 3, 20-VIII-2007, E.B. D'Alessandro (UFG40241); Ponto 2, 26-VIII-2007, E.B. D'Alessandro (UFG40243); Ponto 3, 26-VIII-2007, E.B. D'Alessandro (UFG40244); Ponto 3, 2-IX-2007, E.B. D'Alessandro (UFG40247); Ponto 2, 9-IX-2007, E.B. D' Alessandro (UFG40249); Ponto 3, 16-IX-2007, E.B. D'Alessandro (UFG40253); Ponto 3, 23-IX-2007, E.B. D'Alessandro (UFG40255); Ponto 3, 30-IX-2007, E.B. D'Alessandro (UFG40257).

Distribuição geográfica: Primeira citação da espécie para o Estado de Goiás.

Família Radiococcaceae Fott \& Komárek 1979

Gênero Radiococcus Schimidle 1902

Radiococcus fotti (Hindak) Kostikov, Darienko, Lukešová et Hoffmann. Arch. Hydrobiol. Suppl. 142 (Algol. Stud. 104): 39. 2002.

Figura 6

Colônia arredondada, $24 \mu \mathrm{m}$ de diâmetro, com 2 grupos de (2)-4-8 células dispostas em coroa, em dois planos paralelos, de modo que cada célula de um plano localiza-se sobre o espaço entre duas células do outro plano, em mucilagem hialina, conspícua. Células esféricas, 5-6 $\mu \mathrm{m}$; cloroplasto único, parietal, poculiforme, 1 pirenoide basal. Reprodução por 4 autósporos, esféricos, dispostos em arranjo idênticos ao da colônia, liberados por dissolução da parede da célula-mãe.

Material examinado: BRASIL. GoIÁs: Goiânia, Parque Beija-Flor, Ponto 3, 30-IX-2007, E.B. D'Alessandro (UFG40257); Ponto 2, 7-II-2008, E.B. D'Alessandro (UFG40268).

Distribuição geográfica: citado como Eutetramorus fottii (Hind.) Kom. para o município de Caldas Novas: reservatório de Corumbá (Silva et al. 2001), município de Goiânia: lago do Parque Vaca Brava, lago das Rosas, lago do Bosque dos Buritis (Bazza 1998, Nogueira et al. 2008, Nogueira \& Oliveira 2009). Município de Britânia: lago dos Tigres (Alves et al. 2014).

Família Scenedesmaceae

Gênero Comasiella E.Hegewald \& M.Wolf, 2010. 

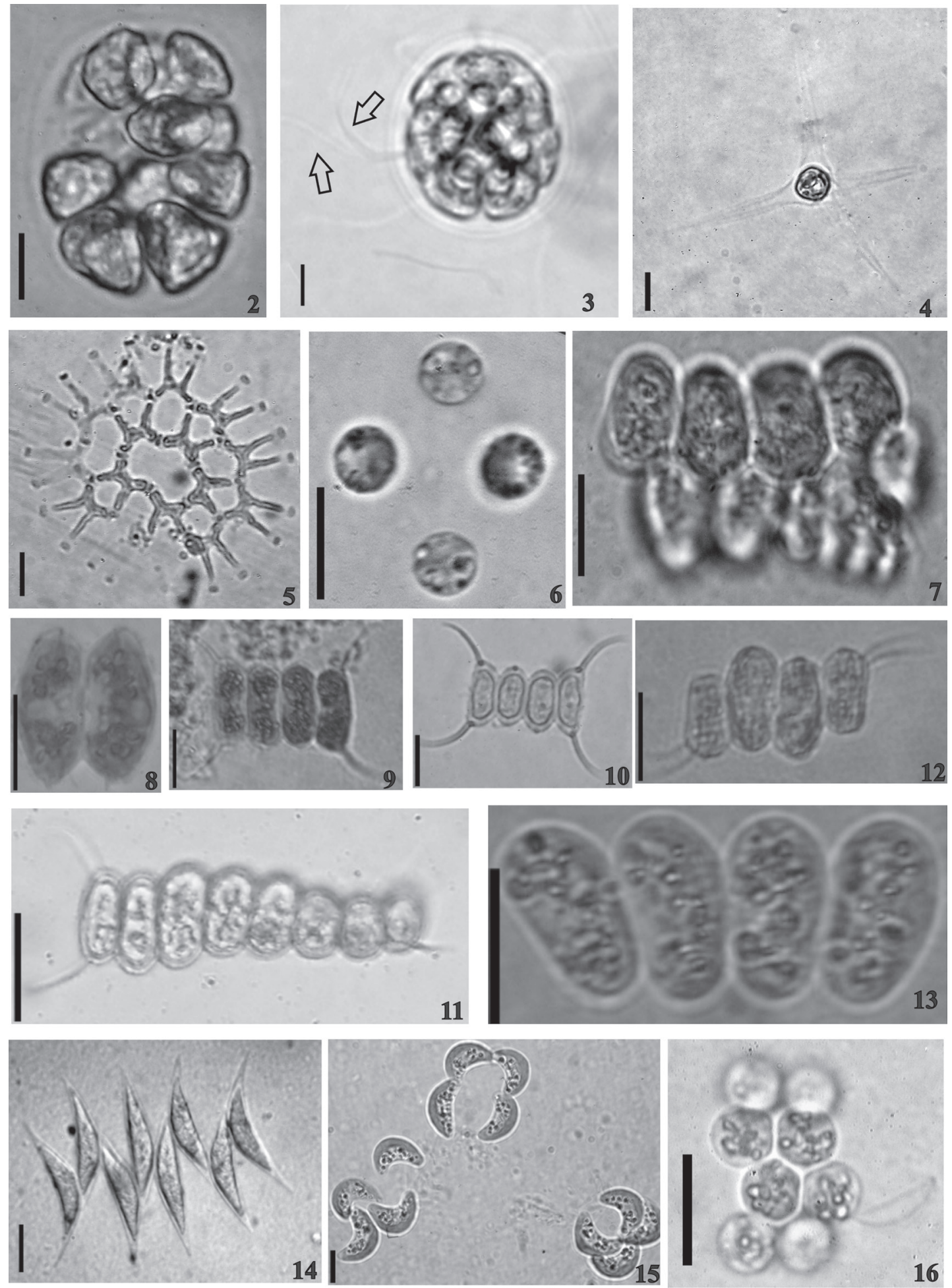

Figuras 2-16. Espécies de Chlorophyta no Parque Beija-Flor, GO, Brasil. 2-3. Pandorina morum. 2. Indivíduo adulto. 3. Indivíduo com flagelos indicados pelas setas. 4. Treubaria schmidlei. 5. Lacunastrum gracillimum. 6. Radiococcus fottii. 7. Comasiella arcuata var. platydisca. 8. Desmodesmus brasiliensis. 9-10. D. communis. 11. D. intermedius. 12. D. intermedius var. acutispinus. 13. Scenedesmus ecornis. 14. Pectinodesmus javanensis var. javanensis. 15. Tetrallantos lagarheimii. 16. Westella botryoides. Escala $=10 \mu \mathrm{m}$.

Figures 2-16. Chlorophyta species in Parque Beija-Flor, Goiás State, Brazil. 2-3. Pandorina morum. 2. Adult individual. 3. Individual with flagella indicated by arrows. 4. Treubaria schmidlei. 5. Lacunastrum gracillimum. 6. Radiococcus fottii. 7. Comasiella arcuata var. platydisca. 8. Desmodesmus brasiliensis. 9-10. D. communis. 11. D. intermedius. 12. D. intermedius var. acutispinus. 13. Scenedesmus ecornis. 14. Pectinodesmus javanensis var. javanensis. 15. Tetrallantos lagarheimii. 16. Westella botryoides. Scale bar $=10 \mu \mathrm{m}$. 
Comasiella arcuata var. platydisca (G.M.Smith) E.Hegewald \& M.Wolf. Phycologia 49(4): 332-333. 2010.

Figura 7

Cenóbio curvo, 1-2 fileiras de 4 células dispostas linearmente, justapostas e as fileiras unindo-se pelos ápices das células. Células reniformes, $12 \times 7 \mu \mathrm{m}$; cloroplasto único, parietal, 1 pirenoide, parede celular lisa, hialina. Reprodução por autósporo.

Material examinado: BRASIL. Goís: Goiânia, Parque Beija-Flor, Ponto 3, 2-IX-2007, E.B. D'Alessandro (UFG40247); Ponto 3, 23-IX-2007, E.B. D'Alessandro (UFG40255); Ponto 3, 30-IX-2007, E.B. D'Alessandro (UFG40257).

Distribuição geográfica: município de Goiânia: represa Samambaia (Souza \& Felisberto 2014).

Gênero Desmodesmus An, Friedl \& Hegewald, 1999.

Desmodesmus brasiliensis (Bohlin) E. Hegewald. Algological Studies 96: 7. 2000.

Figura 8

Cenóbio reto, 2 células disposta linearmente. Células elípticas ou oblongas, unidas entre si em quase a totalidade do comprimento, $16 \times 7 \mu \mathrm{m}, 1$ costela em cada face frontal, fusionando-se com os polos, formando 1 dente, parede celular lisa, cloroplasto único, parietal, 1 pirenoide. Reprodução por autósporo.

Material examinado: BRASIL. Goiás: Goiânia, Parque Beija-Flor, Ponto 3, 30-IX-2007, E.B. D'Alessandro (UFG40257).

Distribuição geográfica: município de Goiânia: lago do Parque Vaca Brava, lago das Rosa, lago do Bosque dos Buritis (Nogueira et al. 2008), represa Samambaia (Souza \& Felisberto 2014).

Desmodesmus communis (Hegew.) E. Hegewald.

Algological Studies 96: 8. 2000.

Figuras 9 e 10

Cenóbio reto, 4 células dispostas linearmente. Células oblongas, unidas entre si em quase a totalidade do comprimento, $12-20 \times 5-8 \mu \mathrm{m}$, polos arredondados, os externos com 2 ou 1 espinhos longos de 10-13 $\mu \mathrm{m}$ de compr., cloroplasto único, parietal, 1 pirenoide, parede celular hialina. Reprodução por autósporo.

Material examinado: BRASIL. GoIÁs: Goiânia, Parque Beija-Flor, Ponto 2, 20-VIII-2007, E.B.
D'Alessandro (UFG40240); Ponto 3, 20-VIII-2007, E.B. D'Alessandro (UFG40241); Ponto 2, 26-VIII-2007, E.B. D'Alessandro (UFG40243); Ponto 3, 26-VIII-2007, E.B. D'Alessandro (UFG40244); Ponto 2, 2-IX-2007, E.B. D'Alessandro (UFG40246); Ponto 3, 2-IX-2007, E.B. D'Alessandro (UFG40247); Ponto 2, 9-IX-2007, E.B. D' Alessandro (UFG40249); Ponto 3, 9-IX-2007, E.B. D'Alessandro (UFG40250), Ponto 3, 16-IX-2007, E.B. D'Alessandro (UFG40253); Ponto 3, 23-IX-2007, E.B. D'Alessandro (UFG40255); Ponto 3, 30-IX-2007, E.B. D'Alessandro (UFG40257); Ponto 3, 7-II-2008, E.B. D'Alessandro (UFG40269).

Distribuição geográfica: Citado como Scenedesmus quadricauda (Turp.) Breb. Município de Goiânia: rio Meia Ponte (Macedo-Saidah et al. 1987, represa Samambaia (Brandão \& Kravchenko 1997, Souza \& Felisberto 2014). Citado como Scenedesmus quadricauda (Turpin) Brébisson sensu Chodat var. quadricauda. Município de Caldas Novas: reservatório de Corumbá (Bazza 1998, Silva et al. 2001), rio Corumbá (Felisberto et al. 2001).

Desmodesmus intermedius (R. Chod.) E. Hegewald. Archiv für Hydrobiologie, Suppl. 131 (Algological Studies) 96: 11. 2000.

Figura 11

Cenóbio reto, $35,5 \mu \mathrm{m}, 8$ células dispostas levemente alternadas. Célula oblonga, 8-10 × 4-5 $\mu \mathrm{m}$, polos arredondados, os externos com 1 espinho em cada, $7 \mu \mathrm{m}$ de compr., cloroplasto único, parietal, 1 pirenoide, parede celular hialina. Reprodução por autósporo.

As características métricas de $D$. intermedius geralmente citada na literatura é em torno de 5 $\mu \mathrm{m}$ de compr., no entanto Tsarenko \& John (2011) apresentaram medidas de até $10 \mu \mathrm{m}$ para esta espécie e Godinho et al. (2010) teve os espécimes com características métricas de $12,8 \mu \mathrm{m}$ de comprimento. No material analisado para Goiás os menores espécimes apresentaram-se com $8 \mu \mathrm{m}$, porém o arranjo dos cenóbios sempre constante na população foi suficiente para identificá-los como $D$. intermedius.

Material examinado: BRASIL. GoIÁs: Goiânia, Parque Beija-Flor, Ponto 2, 20-VIII-2007, E.B. D'Alessandro (UFG40240); Ponto 3, 26-VIII-2007, E.B. D'Alessandro (UFG40244); Ponto 3, 9-IX-2007, E.B. D'Alessandro (UFG40250); Ponto 2, 16-IX-2007, E.B. D'Alessandro (UFG40252); Ponto 3, 16-IX-2007, E.B. D'Alessandro (UFG40253); Ponto 3, 30-IX-2007, E.B. D'Alessandro (UFG40257). 
Distribuição geográfica: município de Goiânia: lago do Jardim Botânico, lago do Parque Vaca Brava, lago das Rosas, lago do Bosque dos Buritis (Nogueira et al. 2008).

Desmodesmus intermedius (R. Chod.) Hegewald var. acutispinus (Roll) Hegewald. Algological Studies 96: 11. 2000.

Figura 12

Cenóbio reto, $20 \mu \mathrm{m}, 4$ células dispostas levemente alternadas. Célula oblonga, 9-12 × 5-7 $\mu \mathrm{m}$, polos arredondados, os externos com 1-2 espinho em um dos polos diagonalmente oposto com o polo da outra célula externa, $8 \mu \mathrm{m}$ de compr.; parede celular hialina, cloroplasto único, parietal, 1 pirenoide. Reprodução por autósporo.

As populações de $D$. intermedius var. acutispinus analisadas neste estudo apresentaram células maiores do que aquelas registradas por Godinho et al. (2010) para material de São Paulo. A presença de dois espinhos em um dos polos das células externas em alguns indivíduos já havia sido registrada por NagyToth (1987) em estudo de culturas para a então espécie $S$. intermedius ( $=D$. intermedius).

Material examinado: BRASIL. GoIÁs: Goiânia, Parque Beija-Flor, Ponto 3, 20-VIII-2007, E.B. D'Alessandro (UFG40241); Ponto 3, 26-VIII-2007, E.B. D'Alessandro (UFG40244); Ponto 3, 2-IX-2007, E.B. D'Alessandro (UFG40247); Ponto 3, 23-IX-2007, E.B. D'Alessandro (UFG40255).

Distribuição geográfica: primeira citação da variedade para o Estado de Goiás.

Pectinodesmus javanensis (Chodat) E.Hegewald, C.Bock \& Krienitz var. javanensis. Fottea 14(2): 151. 2013.

Figura 14

Cenóbio reto, 8 células dispostas em ziguezague. Células lunadas, com $30 \times 5 \mu \mathrm{m}$, sendo os polos internos de cada célula unidos à região mediana convexa da célula vizinha, as células centrais unindo-se pela região mediana convexa; cloroplasto único, parietal, com um pirenoide, parede celular lisa, hialina. Reprodução por autósporo.

Material examinado: BRASIL. Goiás: Goiânia, Parque Beija-Flor, Ponto 3, 26-VIII-2007, E.B. D'Alessandro (UFG40244); Ponto 3, 2-IX-2007, E.B. D'Alessandro (UFG40247); Ponto 3, 23-IX-2007, E.B. D'Alessandro (UFG40255); Ponto 3, 30-IX-2007, E.B. D' Alessandro (UFG40257).
Distribuição geográfica: citado como Scenedesmus javanensis Chodat. Município de Goiânia: ribeirão João Leite (Saneago 1996), lago do Jardim Botânico de Goiânia, lago do Parque Vaca Brava, lago das Rosas, lago do Bosque dos Buritis (Nogueira et al. 2008). Município de Caldas Novas: reservatório de Corumbá (Silva et al. 2001), rio Corumbá (Felisberto et al. 2001).

Scenedesmus ecornis (Ehrenberg) Chodat. Schweizerische Zeitschrift für Hydrologie 3: 170. 1926.

Figura 13

Cenóbio reto, 4 células dispostas linearmente. Células obovadas $12 \times 5,5 \mu \mathrm{m}$, margem das células externas retas a levemente convexas, parede celular lisa; cloroplasto único parietal, 1 pirenoide, parede celular lisa, hialina. Reprodução por autósporo.

Material examinado: BRASIL. GoIÁs: Goiânia, Parque Beija-Flor, Ponto 3, 23-IX-2007, E.B. D'Alessandro (UFG40255).

Distribuição geográfica: município de Caldas Novas: reservatório de Corumbá (Bazza 1998, Silva et al. 2001). Município de Goiânia: represa Samambaia (Souza \& Felisberto 2014).

Gênero Tetrallantos Teiling, 1916.

Tetrallantos lagerheimii Teiling. Svensk Botanisk Tidskrift 10: 62, figs. 1-7. 1916.

Figura 15

Cenóbio de 4 células, duas delas no mesmo plano unidas em ambos os polos, formando um anel; cada região de união ligando-se a 1 polo de outra célula perpendicular ao anel; mucilagem hialina, inconspícua. Células lunadas, $18 \times 7 \mu \mathrm{m}$, ápices arredondados parede celular lisa; cloroplasto único, parietal, 1 pirenoide. Reprodução por 4 autósporos.

Material examinado: BRASIL. GoiÁs: Goiânia, Parque Beija-Flor, Ponto 3, 23-IX-2007, E.B. D'Alessandro (UFG40255); Ponto 3, 30-IX-2007, E.B. D'Alessandro (UFG40257).

Distribuição geográfica: município de Caldas Novas: reservatório de Corumbá (Bazza 1998, Silva et al. 2001). Município de Goiânia: lago do Jardim Botânico, lago do Parque Vaca Brava, lago das Rosas, lago do Bosque dos Buritis (Nogueira et al. 2008).

Gênero Westella De Wildemann, 1892. 
Westella botryoides (W. West) De Wildemann. Bulletin de l'Herbier Boissier 5: 532. 1897.

Figura 16

Cenóbio plano, quadrangular a raramente alongado, 4 células dispostas cruciadamente, espaços intercelulares ausentes ou retangulares, sincenóbios dispostos no mesmo plano ou sobrepostos intercaladamente. Células esféricas, $6 \mu \mathrm{m}$ de diâm.; cloroplasto único, poculiforme, 1 pirenoide. Reprodução por autósporos organizados em 4 cenóbios-filhos dispostos nas células-esporangial, paralelamente ao cenóbio-mãe.

Das amostras estudadas, em uma única delas foi registrado presença de sincenóbios semelhantes ao material registrado por Nogueira (1991) para o Rio de Janeiro e por Ramos et al. (2014) para espécimes da Bahia.

Material examinado: BRASIL. GoiÁs: Goiânia, Parque Beija-Flor, Ponto 3, 30-IX-2007, E.B. D'Alessandro (UFG40257).

Distribuição geográfica: município de Goiânia: ribeirão João Leite (Saneago 1996), lago do Jardim Botânico de Goiânia, lago do Parque Vaca Brava, lago das Rosas, lago do Bosque dos Buritis (Nogueira \& Leandro-Rodrigues 1999, Nogueira et al. 2008).

Família Selenastraceae

Gênero Kirchneriella Schmidle, 1893.

Kirchneriella aperta Teiling. Svensk Botanisk Tidskrift 6(2): 276, fig. 9. 1912.

Figura 17

Colônia alongada ou arredondada, 23,5 $\mu \mathrm{m}$ diâmetro, 4-8 células dispostas irregularmente em mucilagem hialina, inconspícua. Células lunadas, contorno circular, incisão mediana em forma de "V", $8 \times 5 \mu \mathrm{m}, 2 \mu \mathrm{m}$ de distância entre os ápices; cloroplasto único, parietal, 1 pirenoide inconspícuo. Reprodução por 4 autósporos.

Material examinado: BRASIL. GoIÁs: Goiânia, Parque Beija-Flor, Ponto 2, 20-VIII-2007, E.B. D'Alessandro (UFG40240); Ponto 2, 26-VIII-2007, E.B. D'Alessandro (UFG40243).

Distribuição geográfica: município de Goiânia: ribeirão João Leite (Saneago 1996), lago das Rosas (Nogueira et al. 2008).

Kirchneriella diane (Bohlin) Comas var. diane. Acta bot. Cubana, 2: 4. 1980.

Figura 18
Colônia arredondada até alongada, $49 \mu \mathrm{m}$ de diâmetro, de 16-24-32 células agrupadas com ápices orientados para a periferia da colônia, mucilagem hialina, células lunadas com incisão mediana em forma de "U", 5-9 × 5-8 $\mu \mathrm{m}$; cloroplasto único, parietal, 1 pirenoide; parede celular lisa. Reprodução por 4 autósporos.

Material examinado: BRASIL. Goís: Goiânia, Parque Beija-Flor, Ponto 3, 20-VIII-2007, E.B. D'Alessandro (UFG40241); Ponto 3, 26-VIII-2007, E.B. D'Alessandro (UFG40244); Ponto 3, 16-IX-2007, E.B. D'Alessandro (UFG40253); Ponto 3, 23-IX-2007, E.B. D'Alessandro (UFG40255).

Distribuição geográfica: município de Goiânia: ribeirão João Leite (Saneago 1996), lago do Jardim Botânico, lago do Parque Vaca Brava, lago das Rosas, lago do Bosque dos Buritis (Nogueira et al. 2008).

Kirchneriella lunaris (Kirchner) Mobios.

Abhandlungen der Senckenbergischen

Naturforschenden Gesellschaft 18:331. 1894. Figura 19

Colônia arredonda, 17,3 $\mu \mathrm{m}$ de diâmetro, de 4 células agrupadas, com ápices acuminados, aproximadamente orientados para a periferia da colônia, mucilagem hialina, células lunadas, com incisão mediana em forma de "U", $9 \times 5 \mu \mathrm{m}$; cloroplasto único, parietal, 1 pirenoide; parede celular lisa. Reprodução por 4 autósporo.

Os espécimes de $K$. lunaris analisados tiveram proximidade morfológica do contorno celular daqueles ilustrados em Komarek \& Fott (1983), a diferença deste táxon para $K$. dianae reside no tamanho e organização das células e a incisão.

Material examinado: BRASIL. GoIÁs: Goiânia, Parque Beija-Flor, Ponto 3, 2-IX-2007, E.B. D'Alessandro (UFG40247); Ponto 3, 16-IX-2007, E.B. D' Alessandro (UFG40253); Ponto 3, 23-IX-2007, E.B. D' Alessandro (UFG40255).

Distribuição geográfica: município de Caldas Novas: reservatório de Corumbá (Bazza 1998, Silva et al. 2001). Município de Goiânia: bosque dos Buritis (Nascimento-Bessa \& Santos, 1995), lago do Jardim Botânico, lago do Bosque dos Buritis (Nogueira et al. 2008)

Gênero Raphidocelis (Hindák), Marvan, Komárek \& Comas 1984. 

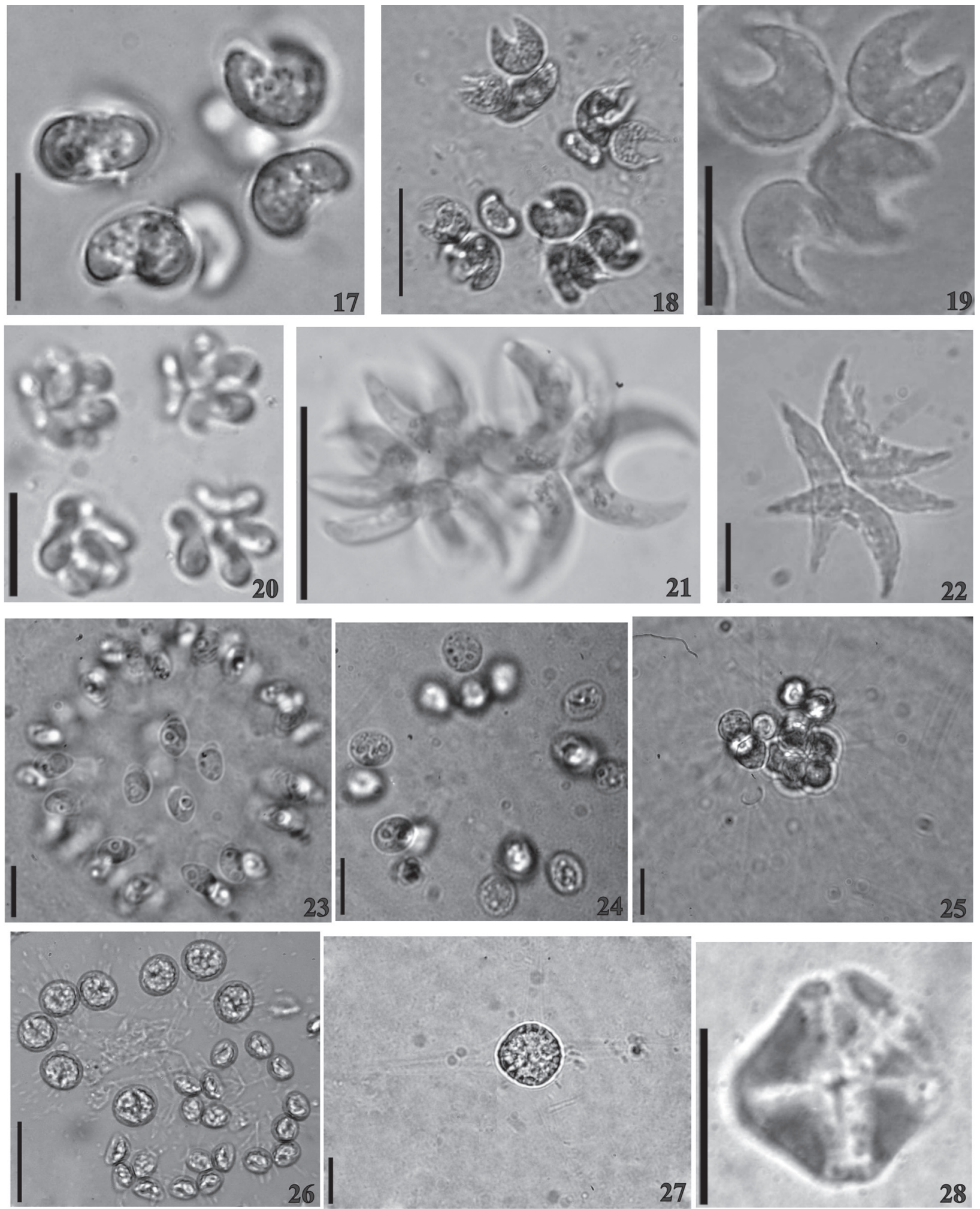

Figuras 17-28. Espécies de Chlorophyta no Parque Beija-Flor, GO, Brasil. 17. Kirchneriella aperta. 18. K. diane. 19. K. lunari.20. Raphidocelis danubiana. 21. Selenastrum rinoi. 22. Dicloster acuatus. 23. Hindakia fallax. 24. H. tetrachotomum. 25. Micractinium pusillum. 26. Mucidosphaerium pulchellum. 27. Pachycladella komarekii. 28. Lemmermannia tetrapedia. Escala $=10 \mu \mathrm{m}$.

Figures 17-28. Chlorophyta species in Parque Beija-Flor, Goiás State, Brazil. 17. Kirchneriella aperta. 18. K. diane. 19. K. lunari. 20. Raphidocelis danubiana. 21. Selenastrum rinoi. 22. Dicloster acuatus. 23. Hindakia fallax. 24. H. tetrachotomum. 25. Micractinium pusillum. 26. Mucidosphaerium pulchellum. 27. Pachycladella komarekii. 28. Lemmermannia tetrapedia. Scale bar $=10 \mu \mathrm{m}$. 
Raphidocelis danubiana (Hindák), Marvan, Komárek \& Comas. Arch. Hydrobiol. Suppl. 67: (Algological Studies 37) 386, fig. 9B: 9 a-e. 1984.

Figura 20

Colônia arredondada, $28 \mu \mathrm{m}, 4$ grupos de 4 células, dispostas lado a lado, com o lado côncavo orientado para o centro da colônia. Células lunadas, $7 \times 4 \mu \mathrm{m}$ com ápices arredondados; cloroplasto único, parietal; pirenoide ausente, parede celular lisa. Reprodução por autósporos.

$R$. daubiana é um táxon pouco registrado no país, destacam-se o registro nos trabalhos de Nogueira \& Leandro-Rodrigues (1999) e Ramos et al. (2014). Os espécimes analisados no Parque Beija-Flor apresentaram configurações morfológicas próximas àquelas registradas por este último trabalho para $\mathrm{o}$ Estado da Bahia.

Material examinado: BRASIL. GoiÁs: Goiânia, Parque Beija-Flor, Ponto 3, 26-VIII-2007, E.B. D'Alessandro (UFG40244); Ponto 3, 2-IX-2007, E.B. D'Alessandro (UFG40247).

Distribuição geográfica: município de Goiânia: jardim botânico Chico Mendes (Nogueira \& LeandroRodrigues 1999).

Selenastrum rinoi Komárek \& Comas. Arch. Hydrobiol. Suppl., 63(3): 276, fig. 10. 1982.

Figura 21

Colônia arredondada a alongada, 16-21 $\mu \mathrm{m}$ de diâmetro, 8-16-32-(64) células, dispostas de forma irregular, com lado convexo orientado para o centro da colônia. Células lunadas ou arqueadas, $6 \times 2 \mu \mathrm{m}$, ápices gradualmente afilados, dispostos no mesmo plano; cloroplasto único, parietal, sem pirenoide. Reprodução por autósporos.

Selenastrum rinoi difere de Selenastrum capricornutum por apresentar células de menor largura, com ápices mais distanciados entre si e por exibirem disposição irregular destas na colônia. Krienitz et al. (2011b) indicaram a tendência da proximidade das características morfológica entre as espécies de $S$. rinoi, $S$. bribraianum e $S$. gracile. Estes autores consideraram necessário um estudo mais acurado de biologia molecular para delimitar a posição diagnóstica destes táxons. Silva et al. (2017) descreveu o gênero Messastrum T. S. Garcia cujo o tipo genérico foi Messastrum gracile (Basionimo e Holotipo $S$. gracile Reinsch 1866). Com o estudo realizado por Silva et al. (2017) considera-se que iniciou a revisão taxonômica no gênero Selenastrum.
Material examinado: BRASIL. GoIÁs: Goiânia, Parque Beija-Flor, Ponto 3, 20-VIII-2007, E.B. D'Alessandro (UFG40241); Ponto 3, 26-VIII-2007, E.B. D'Alessandro (UFG40244); Ponto 3, 23-IX-2007, E.B. D'Alessandro (UFG40255); Ponto 3, 30-IX-2007, E.B. D'Alessandro (UFG40257).

Distribuição geográfica: município de Goiânia: jardim botânico Chico Mendes, lago do Parque Vaca Brava, lago das Rosas (Nogueira \& Leandro-Rodrigues 1999, Nogueira et al. 2008).

Classe Trebouxiophyceae

Ordem Chlorellales

Família Chlorellaceae

Gênero Dicloster Jao, Wei \& Hu, 1976.

Dicloster acuatus Jao, Wei \& Hu. Acta Hydrobiologica Sinica 6(1): 115. 1976.

Figura 22

Cenóbio reto, 2 fileiras de 2 células dispostas de tal forma que a porção de união entre as células de uma fileira intercala-se com a outra. Células lunadas, $22 \times 5 \mu \mathrm{m}$ unidas na porção convexa; cloroplasto único, parietal, 2 pirenoides. Reprodução por autósporos.

Material examinado: BRASIL. GoIÁs: Goiânia, Parque Beija-Flor, Ponto 3, 2-IX-2007, E.B. D'Alessandro (UFG40247).

Distribuição geográfica: município de Goiânia, lago do Parque Vaca Brava, lago das Rosas, lago do Bosque dos Buritis (Nogueira et al. 2008).

Gênero Hindakia Bock, Proschold \& Krienitz, 2010.

Hindakia fallax (Komárek) Bock, Proschold \& Krienitz. European Journal of Phycology 45(3): 271, fig.6. 2010.

Figura 23

Colônia arredondada, 48-57 $\mu \mathrm{m}$ de diâmetro. Células agrupadas de 1-2-4-8-16 grupos 4 células conectadas por pedúnculo mucilaginoso, hialino. Células adultas obovado-alargada, $8 \times 6 \mu \mathrm{m}$, cloroplasto único, poculiforme, com 1 pirenoide distinto; parede celular lisa, hialina. Células filhas idênticas às adultas. Reprodução por autósporos.

Material examinado: BRASIL. Goís: Goiânia, Parque Beija-Flor, Ponto 2, 20-VIII-2007, E.B. D'Alessandro (UFG40240); Ponto 2, 26-VIII-2007, E.B. D'Alessandro (UFG40243); Ponto 2, 9-IX-2007, E.B. D'Alessandro (UFG40249); Ponto 3, 16-IX-2007, 
E.B. D'Alessandro (UFG40253); Ponto 3, 23-IX-2007, E.B. D'Alessandro (UFG40255); Ponto 3, 30-IX-2007, E.B. D'Alessandro (UFG40257).

Distribuição geográfica: citado como Dictyosphaerium tetrachotomum Printz var. fallax Komárek. Município de Goiânia: Lago das Rosas, lago do Bosque dos Buritis e lago do Jardim Botânico (Nogueira \& Oliveira 2009).

Hindakia tetrachotomum (Printz) Bock, Proschold \& Krienitz. European Journal of Phycology 45(3): 270. 2010.

Figura 24

Colônia arredondada, $36 \mu \mathrm{m}$ e diâmetro. Células agrupadas 1, 2, 4 grupos de 4 células conectadas por pedúnculo mucilaginoso, hialino. Células adultas oblongas a oblongo-alargadas, $8 \times 6 \mu \mathrm{m}$, cloroplasto único, poculiforme, com 1 pirenoide distinto; parede celular lisa, hialina. Células jovens idênticas às adultas. Reprodução por autósporos.

Material examinado: BRASIL. GoIÁs: Goiânia, Parque Beija-Flor, Ponto 3, 16-IX-2007, E.B. D'Alessandro (UFG40253); Ponto 3, 23-IX-2007, E.B. D'Alessandro (UFG40255); Ponto 3, 30-IX-2007, E.B. D'Alessandro (UFG40257).

Distribuição geográfica: citado como Dictyosphaerium tetrachotomum Printz. Município de Caldas Novas: reservatório de Corumbá (Silva et al. 2001). Município de Goiânia: lago do Jardim Botânico de Goiânia, lago do Parque Vaca Brava, lago das Rosas, lago do Bosque dos Buritis (Nogueira et al. 2008).

Gênero Micractinium Fresenius, 1858.

Micractinium pusillum Fresenius. Abhandlungen der Senckenbergischen Naturforschenden Gesellschaft 2: 236, pl. XI, figs. 46-49. 1858.

Figura 25

Colônia tetraédrica, quadrática, ou células agregadas, 26-35 $\mu \mathrm{m}$ de diâmetro (incluindo os espinhos), com (2)-4-8-16-(32) células justapostas. Células esféricas, 6-7 $\mu \mathrm{m}, 2-3$ espinhos retos, 11-33 $\mu \mathrm{m}$, tênues, longos, dispostos na margem livre; cloroplasto único, poculiforme, 1 pirenoide esférico. Reprodução por 4 autósporos, esféricos, dispostos tetraedricamente.

Material examinado: BRASIL. GoIÁs: Goiânia, Parque Beija-Flor, Ponto 3, 2-IX-2007, E.B. D'Alessandro (UFG40247); Ponto 3, 16-IX-2007, E.B. D'Alessandro (UFG40253).
Distribuição geográfica: município de Caldas Novas: reservatório de Corumbá (Bazza 1998, Silva et al. 2001). Município de Goiânia: lago do Jardim Botânico, lago das Rosas, lago do Bosque dos Buritis (Nogueira et al. 2008). Município de Inhumas: lagoa de estabilização (Crispin et al. 1992).

Gênero Mucidosphaerium Bock, Proschold \& Krienitz, 2011

Mucidosphaerium pulchellum (Wood), Bock, Proschold \& Krienitz. Journal of Phycology 47(3): 642. 2011.

Figura 26

Colônia arredondada, 40-48,5 $\mu \mathrm{m}$ de diâmetro, 1-2-4-8 grupos de 4 células unidas entre si por pedúnculo mucilaginoso, hialino. Células adultas esféricas, 5-6 $\times 5 \mu \mathrm{m}$, cloroplasto único, poculiforme, com 1 pirenoide, parede celular hialina. Células jovens oblongas a ovais. Reprodução por autósporo.

Material examinado: BRASIL. GoIÁs: Goiânia, Parque Beija-Flor, Ponto 2, 20-VIII-2007, E.B. D'Alessandro (UFG40240); Ponto 2, 26-VIII-2007, E.B. D'Alessandro (UFG40243); Ponto 3, 26-VIII-2007, E.B. D'Alessandro (UFG40244); Ponto 3, 2-IX-2007, E.B. D'Alessandro (UFG40247); Ponto 3, 9-IX-2007, E.B. D' Alessandro (UFG40250); Ponto 3, 16-IX-2007, E.B. D'Alessandro (UFG40253); Ponto 3, 23-IX-2007, E.B. D'Alessandro (UFG40255); Ponto 3, 30-IX-2007, E.B. D'Alessandro (UFG40257).

Distribuição geográfica: citado como Dictyosphaerium pulchellum Wood. Município de Caldas Novas: reservatório de Corumbá (Silva et al. 2001). Município de Goiânia: lago do Jardim Botânico, lago do Parque Vaca Brava, lago das Rosas, lago do Bosque dos Buritis (Nogueira \& Leandro-Rodrigues 1999, Nogueira et al. 2008).

Família Oocytaceae

Gênero Pachycladella (G. M. Smith) Silva, 1970

Pachycladella komarekii (Fott \& Kovác.) Reymond. Candollea 35: 66. 1980.

Figura 27

Célula isolada, livre, tetraédrica ou esférica, $15 \mu \mathrm{m}$ de diâmetro, 4 processos pontiagudos, hialinos, retos, $27 \times 7 \mu \mathrm{m}$, parede celular lisa, hialina, distinta dos processos; protoplasma justaposto a parede celular; cloroplasto único, parietal, 1 pirenoide. Reprodução por autósporos. 
Pachycladella komarekii (Fott \& Kovác.) Reymond ainda não foi registrado na litertura brasileira. Fazendo uma análise das medias métricas observadas na população estudada, notou-se que foram constates e apresentaram-se maiores tanto em diâmetro da célula quanto no comprimento dos processo. No entanto as demais caracteristicas foram condizentes com aquelas registradas em Komárek \& Fott (1983). Pachycladella difere da Treubaria somente pela análise morfológica da região de conexão dos espinhos ou processos e do distanciamento do citoplasma da parede celular. Em Treubaria os espinhos hialinos são indistintos da parede e apresenta o protoplasma centralizado e afastado da parede. Em Pachycladella os processos são nitidamente distintos da parede celular e apresenta o conteúdo protoplasmático adjacente a este envoltório celulósico.

Material examinado: BRASIL. GoIÁs: Goiânia, Parque Beija-Flor, Ponto 3, 23-IX-2007, E.B. D'Alessandro (UFG40255).

Distribuição geográfica: Primeira citação da espécie para o Estado de Goiás.

Família Trebouxiophyceae incertae sedis

Gênero Lemmermannia Chodat 1900

Lemmermannia tetrapedia (Kirchner) Lemmermann. Arkiv för Botanik, Uppsala 2 (2): 157. 1904. Figura 28

Cenóbio reto, cruciado, quadrático, espaço intercelular ausente, 4 células triangulares, $5 \times 7 \mu \mathrm{m}$, cloroplasto único, parietal, situado no lado externo da célula, pirenoide ausente; parede celular lisa. Reprodução por autósporo.

Material examinado: BRASIL. GoIÁs: Goiânia, Parque Beija-Flor, Ponto 1, 30-IX-2007, E.B. D'Alessandro (UFG40256).

Distribuição geográfica: citado como Crucigenia tetrapedia (Kirch.) West \& G.S. West. Município de Caldas Novas: reservatório de Corumbá (Silva et al. 2001), lago das Rosas (Nogueira et al. 2008).

\section{Considerações finais}

No Brasil, estudos florísticos do fitoplâncton deparam-se com problemas relacionados ao posicionamento taxonômico de muitas espécies. Diante disto, as publicações nesta linha de pesquisa ficaram limitadas a identificação dos táxons de Chlorophyta em famílias e gêneros de tradicional posicionamento fundamentado no sistema de Komárek \& Fott (1983). O sistema proposto por Krienitz \& Bock (2012) reposiciona os gêneros em afinidades filogenéticas, mas encontra-se ainda em desenvolvimento tendo como barreira o posicionamento destes em diferentes famílias. Com isso, Chlorophyta de água doce presente na flora brasileira está tendo sérios problemas no que tange as identidades de gênero e de espécies.

Artigos como os de Rodrigues et al. (2010), Ramos et al. (2014), Aquino et al. (2014), Ramos et al. (2016) dentre outros trazem à flora brasileira melhor expressão de atualização dos nomes científicos, porém alguns ainda mantiveram uma adaptação do sistema de Komárek \& Fott (1983) com o de Krienitz \& Bock (2012). Considerando que Chlorophyta de água doce tem maior representatividade em ecossistemas artificiais no país, o mesmo ocorre no Estado de Goiás (Nogueira \& Leandro-Rodrigues 1999, Nogueira \& Oliveira 2009, Nogueira et al. 2008).

O Parque Beija-Flor compostos por 3 ambientes artificiais, cujo posicionamento geográfico é próximo apresenta nos três pontos amostrais uma composição florística muito semelhante (ponto 2 e ponto 3 ). $\mathrm{O}$ baixo número de espécies de Chlorophyta cocoides e flageladas provavelmente esteja relacionado às condições do período amostral coincidir ainda com a instalação deste ecossistema artificial. Do total de táxon identificados, $92 \%$ foi registrado no ponto 3 , que por ser um corpo d'água menor, proporcionou maior concentração das algas (64\% dos táxons). O efeito diluidor das chuvas resultou em menor riqueza taxonômica $(6 \%)$ neste período, enquanto que na seca foi observada a maior riqueza ( $96 \%$ dos táxons). Radiococcsu fottii e Desmodesmus communis foram as únicas espécies presentes nos dois períodos climáticos.

Como em 2007 o Parque Beija-Flor era um ambiente novo, o ponto 1 (maior extensão e volume de água) apresentou baixa representatividade de Chlorophyta (4\%), cujos táxons foram exclusivos do período de seca. Durante estas amostragens outros grupos algais foram mais representativos como, por exemplo, diatomáceas. Observa-se que em lagos artificiais mais antigos foram registradas maior riqueza taxonômica de Chlorophyta cocoides devido a estabilidade e a disponibilidade de nutrientes acumulados nestes ambientes, como pode-se notar em vários artigos nacionais (Tucci et al. 2006, Nogueira \& Oliveira 2009, Nogueira et al. 2008, Menezes et al. 2011, Tucci et al. 2015, entre outros).

Provavelmente com o passar do tempo poderá observar o incremento de Chlorophyta nos corpos 
hídricos do Parque Beija-Flor, o qual está inserido em uma linha de pesquisa continua sobre lagos artificiais urbanos de Goiás. Esse trabalho apresentou os táxons Pandorina morum, Lacunastrum gracillimum, Desmodesmus intermedius var. acutispinus e Pachycladella komarekii como primeira citação de ocorrência para o Estado de Goiás.

\section{Literatura citada}

Alves-da-Silva, S.M. \& Hahn, A.T. 2001. Lista das Euglenophyta registradas em ambientes de águas continentais e costeiras do Estado do Rio Grande do Sul, Brasil. Iheringia, série Botânica 55: 171-188.

Alves-da-Silva, S.M. \& Hahn, A.T. 2004. Study of Euglenophyta in the Jacuí Delta State Park, Rio Grande do Sul, Brasil. 1. Euglena Ehr., Lepocinclis Perty. Acta Botanica Brasilica 18: 123-140.

Alves-da-Silva, S.M. \& Bridi, F.C. 2004a. Estudo de Euglenophyta no Parque Estadual Delta do Jacuí, Rio Grande do Sul, Brasil. 2. Os gêneros Phacus Dujardin e Hyalophacus (Pringheim) Pochman. Iheringia, série Botânica 59: 75-96.

Alves-da-Silva, S.M. \& Bridi, F.C. 2004b. Euglenophyta no Parque Estadual Delta do Jacuí, Rio Grande do Sul, Sul do Brasil. 3. Strombomonas Defl. Acta Botânica Brasilica 18: 555- 572.

Alves-da-Silva, S.M. \& Schüler-da-Silva, A. 2007. Novos registros do gênero Trachelomonas Ehr. (Euglenophyceae) no Parque Estadual Delta do Jacuí e no Rio Grande do Sul, Brasil. Acta Botanica Brasilica 21: 401-409.

Alves, F.R.R., Gama Jr, W.A. \& Nogueira, I.S. 2014. Planktonic Radiococcaceae Fott ex Komárek of the Tigres Lake system, Britânia, Goiás State, Brazil. Brazilian Journal of Botany 37: 519-530.

Amma (Agência Municipal do Meio Ambiente). 2004. Memorial Descritivo do Parque Beija-Flor. Goiânia, AMMA, Núcleo de Arquitetura e Engenharia.

Amma (Agência Municipal do Meio Ambiente). 2016. Parques e Bosques. Disponível em http://www.goiania. go.gov.br/shtml/amma/parquesebosques.shtml (acesso em 28-IX-2016).

Aquino, C.A.N., Bueno, N.C. \& Menezes, V.C. 2014. Chlorococcales sensu latu (Chlorophyceae) de um ecossistema lótico subtropical, Estado do Paraná, Brasil. Hoehnea 41: 431-451.

Bazza, E. L. 1998. Flutuações na estrutura da comunidade fitoplanctônica durante o período de enchimento do reservatório de Corumbá (GO). Monografia de Bacharelado, Universidade Estadual de Maringá, Maringá.

Bicudo, C.E.M. 2012. Criptógamos do Parque Estadual das Fontes do Ipiranga, São Paulo, SP, Brasil: Algas, 33: Chlorophyceae (famílias Palmellaceae, Hormotilaceae e Dictyosphaeriaceae). Hoehnea 39: 565-575.
Bicudo, C.E.M. \& Menezes, M. 2006. Gênero de algas de água continentais do Brasil (chave para identificação e descrições). 2 ed. RiMa, São Carlos.

Bock, C., Luo, W., Kusber, W-H., Hegewald, E., Pazoutová, M. \& Krienitz, L. 2013. Classification of crucigenoid algae: phylogenetic position of the reinstated genus Lemmermannia, Tetrastrum spp. Crucigenia tetrapedia, and C. lauterbornii (Trebouxiophyceae, Chlorophyta). Journal of Phycology 49: 329-339.

Bock, C., Pröschold, T. \& Krienitz, L. 2010. Two new Dictyosphaerium-morphotype lineages of the Chlorellaceae (Trebouxiophyceae): Heynigia gen. nov. and Hindakia gen. nov. European Journal of Phycology 45: 267-277.

Brandão, D. \& Kravchenko, A. 1997. A biota do Campus Samambaia: história, situação e perspectivas. SegrafUFG, Goiânia.

Buchheim M.A., Michalopulos, E.A. \& Buchheim, J.A. 2001. Phylogeny of the Chlorophyceae with special reference to the Sphaeropleales: a study of $18 \mathrm{~S}$ and $26 \mathrm{~S}$ rDNA data. Journal of Phycology 37: 819-835.

Campos, I.F.P. \& Macedo-Saidah, F.F. 1990. Flórula da represa da escola de agronomia da Universidade Federal de Goiás, Goiânia, Goiás, Brasil. In: Anais do XXXVI Congresso Nacional de Botânica de Curitiba, IBAMA/ SBB, Brasília, pp. 839-857.

Comas, A. 1996. Las chlorococcales dulciacuícolas de Cuba. Bibliotheca Phycologia 99:1-100.

Crispim, W.M.C., Rebouças-Bessa, M.R. \& Osório, N.B. 1992. Avaliação do comportamento de um sistema de lagoa de estabilização em série tratando esgotos domésticos, Região Centro-Oeste do Brasil. In: V Simpósio Luso-Brasileiro de Engenharia Sanitária Ambiental, SESA, Lisboa, pp. 163-173.

Dellamano-Oliveira, M.J., Vieira, A.A., Rocha, O., Colombo, V. \& Sant'Anna, C.L. 2008. Phytoplankton taxonomic composition and temporal changes in a tropical reservoir, Brazil. Fundamental and Applied Limnology 171: 27-38.

Domingues, C.D. \& Torgan, L.C. 2012. Chlorophyta de um lago artificial hipereutrófico no sul do Brasil. Iheringia, Série Botânica 67: 75-91.

Ettl, H. 1983. Chlorophyta I. In: H. Ettl, J. Gerloff, H. Heynig \& D. Mollenhauer (ed.). Süsswasserflora von Mitteleuropa. Band 9, Gustav Fischer Verlag. Stuttgart.

Felisberto, S.A. \& Rodrigues, L. 2002. Desmidiales (exceto o gênero Cosmarium) perifíticas no reservatório de Corumbá, Goiás, Brasil. Iheringia, Série Botânica 57: 75-97.

Felisberto, S.A., Rodrigues, L. \& Leandrini, J.A. 2001. Chlorococcales registradas na comunidade perifítica, no reservatório de Corumbá, Estado de Goiás, Brasil, antes e após o represamento das águas. Acta Scientiarum, Biological Science 23: 275-282. 
Ferragut, C., Lopes, M.R.M., Bicudo, D.C., Bicudo, C.E.M. \& Vercelino, I.S. 2005. Ficoflórula perifítica e planctônica (exceto Bacillariophyceae) do Lago do IAG, Parque Estadual das Fontes do Ipiranga, São Paulo. Hoehnea 32: 137-184.

Ferreira, A.C.S. \& Menezes, M. 2000. Flora planctônica de um reservatório eutrófico, lagoa Guandu, município de Nova Iguaçu, RJ. Hoehnea 27: 45-76.

Gentil, R.C., Tucci, A. \& Sant'Anna, C.L. 2008. Dinâmica da comunidade fitoplanctônica e aspectos sanitários de um lago urbano eutrófico em São Paulo, SP. Hoehnea 35: 265-280.

Giani, A., Figueredo, C.C. \& Eterovick, P.C. 1999. Algas planctônicas do reservatório da Pampulha (MG): Euglenophyta, Chrysophyta, Pyrrophyta, Cyanobacteria. Revista Brasileira de Botânica 22: 107-116.

Godinho, L.R., Gonzáles, A.C. \& Bicudo, C.E.M. 2010. Criptógamos do Parque Estadual das Fontes do Ipiranga, São Paulo, SP. Algas, 30: Chlorophyceae (família Scenedesmaceae). Hoehnea 37: 513-553.

Graham L.E., Graham, J. \& Wilcox, L.W. 2009. Algae. 2 ed. Benjamin Cummings Press, San Francisco.

Hassal, C. 2014. The ecology and biodiversity of urban ponds. WIREs Water 1:187-206.

Hegewald, E., Wolf, M., Keller, A., Friedl, T. \& Krienitz, L. 2010. ITS2 sequence-structure phylogeny in the Scenedesmaceae with special reference to Coelastrum (Chlorophyta, Chlorophyceae), including the new genera Comasiella and Pectinodesmus. Phycologia 49: 325-335.

Hentschke, G.S. \& Torgan, L.C. 2010. Chlorococcales lato sensu (Chlorophyceae, excl. Desmodesmus e Scenedesmus) em ambientes aquáticos na Planície Costeira do Rio Grande do Sul, Brasil. Iheringia, Série Botânica 65: 87-100.

Hentschke, G.S. \& Prado, J.F. 2012. Chlorococcales s. 1. (Chlorophyceae) e Zygnematales (Zygnematophyceae) em um açude do Balneário do Lérmen, Rio Grande do Sul, Brasil. Iheringia, Série Botânica 67: 59-74.

Hindák, F. 1984. Studies on the chlorococcal algae (Chlorophyceae) III. Biologic Prace Slovensky 30: 1-308.

Hindák, F. 1988. Studies on the chlorococcal algae (Chlorophyceae ) IV. Biologic Prace Slovensky 34: 1-263.

Hindák, F. 1990. Studies on the chlorococcal algae (Chlorophyceae ) V. Biologic Prace Slovensky 36: 1-225.

Keppeler, E.C., Lopes, M.R.M. \& Lima, C.S. 1999. Ficoflórula do Lago Amapá em Rio Branco-Acre, I: Euglenophyceae. Revista Brasileira de Biologia 59: 679-686.

Komárek, J. 1983. Contribution to the Chlorococcal algae of Cuba. Nova Hedwigia 37: 65-179.
Komárek, J. \& Fott, B. 1983. Chorophyceae (Grünalgen), Ordiniung: Chlorococcales, In: G. HuberPestalozzi (ed.). Das Phytoplankton des Süsswaser: Systematik und Biologie Pt 7. E. Schwiezerbat'sche Verlagsbuchhandlung, Stuttgart 1: 1-1044.

Kostikovi, I., Darienko, T., Lukesová, A. \& Hoffmann, L. 2002. Revision of the classification system of Radiococcaceae Fott ex Komárek (except the subfamily Dictyochlorelloideae) (Chlorophyta). Algological Studies 104: 23-58.

Krienitz, L. \& Bock, C. 2012. Present state of the systematics of planktonic coccoid green algae of inland waters. Hydrobiologia 698: 295-326.

Krienitz, L., Bock, C., Kotut, K., Pröschold, T. 2012. Genotypic diversity of Dictyosphaerium-morphospecies (Chlorellaceae, Trebouxiophyceae) in African inland waters, including the description of four new genera. Fottea, Olomouc 12: 231-253.

Krienitz, L., Bock, C., Dadheech, P.K., Pröschold, T. 2011a. Taxonomic reassessment of the genus Mychonastes (Chlorophyceae, Chlorophyta) including the description of eight new species. Phycologia 50: 89-106.

Krienitz, L., Bock, C., Nozaki, H., Wolf, M. 2011b. SSU rRNA gene phylogeny of morphospecies affiliated to the bioassay alga "Selenastrum capricornutum" recovered the polyphyletic origin of crescent-shaped chlorophyta. Journal of Phycology 47: 880-893.

Lopes, M.R.M., Bicudo, C.E.M. \& Ferragut, C. 2005. Spatial and temporal variation of phytoplankton in a shallow tropical oligotrophic reservoir, southeast Brazil. Hydrobiologia 542: 235-247.

Macedo-Saidah, F.E.M., Nascimento-Bessa, M.R.R. \& Campos, I.F.P. 1987. O plâncton das águas do Rio Meia Ponte, Município de Goiânia, Goiás, Brasil. Nerítica 2: $105-117$.

Matsuzaki, M., Mucci, J.L.N. \& Rocha, A.A. 2004. Comunidade fitoplanctônica de um pesqueiro na cidade de São Paulo. Revista Saúde Pública 38: 679-86

Menezes, V.C., Bueno, N.C., Bortolini, J.C. \& Godinho, L.R. 2011. Chlorococcales sensu lato (Chlorophyceae) em um lago artificial urbano, Paraná, Brasil. Iheringia, Série Botânica 66: 227-240.

Menezes, M., Bicudo, C.E.M. \& Moura, C.W.N. 2015. Update of the brazilian floristic list of algae and cyanobacteria. Rodriguésia 66: 1047-1062.

Nabout, J.C. \& Nogueira, I.S. 2011. Variação temporal da comunidade fitoplanctônica em lagos urbanos eutróficos. Acta Scientiarum, Biological Sciences 33: 383-391.

Nagy-Tóth, F. 1987. Notes on the pleomorphism of Scenedesmus intermedius Chod. Veröffentlichungen der Arbeitsgemeinschaft Donauforschung 7: 325-342.

Nardini, M.J. \& Nogueira, I.S. 2008. Processo antrópico de um lago artificial e o desenvolvimento da eutrofização e floração de algas azuis em Goiânia, Goiás, Brasil. Estudos 35: 23-52. 
Nascimento-Bessa, M.R.R.N. \& Santos, C.R.A. 1995. Fitoplâncton e fatores fisíco-químicos em lagos do Bosque dos Buritis no município de Goiânia, GoiásBrazil. In: Anais do Word-Wide Symposium Pollution in Large Cities, Science and Technology for Planning Environmental Quality. Venice, pp.17-26.

Nogueira, I.S. 1991. Chlorococcales sensu lato (chlorophyceae) do Município do Rio de Janeiro e arredores, Brasil: inventário e considerações taxonômicas. Dissertação de Mestrado, Universidade Federal do Rio de Janeiro, Rio de Janeiro.

Nogueira, I.S. \& Leandro-Rodrigues, N.C. 1999. Algas planctônicas de um lago artificial do Jardim Botânico Chico Mendes, Goiânia, Goiás: florística e algumas considerações ecológicas. Revista Brasileira de Biologia 59: 377-395.

Nogueira, I.S., Nabout, J.C., Oliveira, J.E. \& Silva, K.D. 2008. Diversidade (alfa, beta e gama) da comunidade fitoplanctônica de quatro lagos artificiais urbanos do município de Goiânia, GO. Hoehnea 35: 55-69.

Nogueira, I.S. \& Oliveira, J.E. 2009. Chlorococcales e Ulothricales de hábito colonial de quatro lagos artificiais do município de Goiânia - GO. Iheringia, Série Botânica 64: 123-143.

Nogueira, I.S., Silva, K.D., Nabout, J.C. \& NascimentoBessa, M.R.R.N. 2002. Cyanobacterias potencialmente tóxicas em diferentes mananciais do estado de Goiás Brasil. In: J.M.P Vieira, A.C. Rodrigues, A.C.C. Silva (org.). Uso sustentável da água. Anais do $10^{\circ}$ Simpósio Luso-Brasileiro de Engenharia Sanitária e Ambiental. Tema 5 - Gestão Ambiental e Saúde Pública, Braga.

Padisák, J., Crossetti, L.O. \& Naselli-Flores, L. 2009. Use and misuse in the application of the phytoplankton functional classification: a critical review with updates. Hydrobiologia 621: 1-19.

Paul, W.J, Hamilton, D.P., Ostrovsky, I., Miller, S., Zhang, A. \& Muraoka, K. 2012. Catchment land use and trophic state impacts on phytoplankton composition: a case study from the Rotorua lakes' district, New Zealand. Hydrobiologia 698: 133-146.

Pröschold, T. \& Leliaert, F. 2007. Systematics of the green algae: conflict of classic and mondern approaches. In: J. Brodie \& J. Lewis (eds.). Unravelling the algae: the past, present and future of algal systematics. CRC press, Boca Raton, pp. 123-153.

Ramírez, J.J.R. \& Bicudo, C.E.M. 2002. Variation of climatic and physical co-determinants of phytoplankton community in four nictemeral sampling days shallow tropical reservoir, Southeastern Brazil. Brazilian Journal of Biology 62: 1-14.

Ramos, G.J.P., Bicudo, C.E.M., Góes-Neto, A. \& Moura, C.W.N. 2014. New additions of coccoid green algae to the phycoflora of Brazil and the Neotropics. Acta Botanica Brasilica 28: 8-16.
Ramos, G.J.P., Bicudo, C.E.M., \& Moura, C.W.N. 2015 a. Scenedesmaceae (Chlorophyta, Chlorophyceae) de duas áreas do Pantanal dos Marimbus (Baiano e Remanso), Chapada Diamantina, Estado da Bahia, Brasil. Hoehnea 42: 549-566.

Ramos, G.J.P., Bicudo, C.E.M., \& Moura, C.W.N. 2015b. Novos registros de algas verdes cocoides (Chlorophyceae, Chlorophyta) para o estado da Bahia e para o Brasil. Sitientibus, série Ciências Biológicas, 15: 1-13.

Ramos, G.J.P., Bicudo, C.E.M., Goes-Neto, A. \& Moura, C.W.N. 2016. Hydrodictyaceae (Chlorophyceae, Chlorophyta) do Pantanal dos Marimbus, Chapada Diamantina, Bahia, Brasil. Iheringia, Série Botânica 71: 13-21.

Riediger, W., Bueno, N.C., Jati, S., Sebastien, N.Y. 2014. Fitoplâncton de lagoas de estabilização da Estação de Tratamento de Esgoto (ETE) no oeste do Paraná, Brasil: classes Chlorophyceae e Euglenophyceae. Iheringia, Série Botânica 69: 329-340.

Reynolds, C.S. 2006. The Ecology of Phytoplankton. Cambridge University Press, Cambridge.

Rodrigues, L.L., Sant'anna, C.L. \& Tucci, A. 2010. Chlorophyceae das represas Billings (Braço Taquacetuba) e Guarapiranga, SP, Brasil. Revista Brasileira de Botânica 33: 247-264.

Rosini, E.F., Sant'Anna, C.L. \& Tucci, A. 2012. Chlorococcales (exceto Scenedesmaceae) de pesqueiros da região Metropolitana de São Paulo, SP, Brasil: levantamento florístico. Hoehnea 39: 11-38.

Rosini, E.F., Sant'Anna, C.L. \& Tucci, A. 2013. Scenedesmaceae (Chlorococcales, Chlorophyceae) de pesqueiros da Região Metropolitana de São Paulo, SP, Brasil: levantamento florístico. Hoehnea 40: 661-678.

Ruggiero, M.A., Gordon, D.P., Orrell, T.M., Bailly, N., Bourgoin, T., Brusca, R.C., Cavalier-Smith, T., Guiry, M.D. \& Kirk, P.M. 2015. A Higher Level Classification of All Living Organisms. Plos One 10: $1-60$.

Saneago (Saneamento de Goiás S.A). 1996. Relatório do Monitoramento do Ribeirão João Leite - Período 94-95. Goiânia.

Silva, C.A., Train, S. \& Rodrigues, L.C. 2001. Estrutura e dinâmica da comunidade fitoplanctônica a jusante e montante do reservatório de Corumbá, Caldas Novas, Estado de Goiás, Brasil. Acta Scientiarum, Biological Science 23: 283-290.

Silva, L.H.S. 1999. Fitoplâncton de um reservatório estrófico (Lago Monte Alegre), Ribeirão Preto, São Paulo, Brasil. Revista Brasileira de Biologia 59: 281-303. 
Silva, T.G., Bock, G., Sant'Anna, C.L., Bagatini, I.L., Wodniok, S. \& Vieira, A.A.H. 2017. Selenastraceae (Sphaeropleales, Chlorophyceae): rbcL, 18S rDNA and ITS-2 secondary structure enlightens traditional taxonomy, with description of two new genera, Messastrum gen. nov. and Curvastrum gen. nov. Fottea 17: 1-19.

Souza, D.B.S. \& Felisberto, S.A. 2014. Comasiella, Desmodesmus, Pectinodesmus e Scenedesmus na comunidade perifítica em ecossistema lêntico tropical, Brasil Central. Hoehnea 41: 109-120.

Tsarenko, P.M. \& John, D.M. 2011. Phylum Chlorophyta (Green Algae) Order Sphaeropleales. In: D.M. John, B.A Whitton \& A.J. Brook (eds.). The Freshwater Algal Flora of the British Isles. 2 ed. Cambridge University Press, Cambridge, pp. 461-465.
Tucci, A., Bento, N.R.M., Rosal, C. \& Bicudo, C.E.M. 2014. Criptógamos do Parque Estadual das Fontes do Ipiranga, São Paulo, SP. Algas 34: Chlorophyceae (Golenkiniaceae e Micractiniaceae). Hoehnea 41: 307-314.

Tucci, A., Sant'anna, C.L., Gentil, R.C. \& Azevedo, M.T.P. 2006. Fitoplâncton do Lago das Garças, São Paulo, Brasil: um reservatório urbano e eutrófico. Hoehnea 33: 147-175.

Tucci, A., Sawatani, M., Rosini, E.F., Lopes, R.I. \& Bicudo, C.E.M. 2015. Criptógamos do Parque Estadual das Fontes do Ipiranga, São Paulo, SP, Brasil. Algas 41: Chlorophyceae (Oocystaceae). Hoehnea 42: 603-614. 